\title{
EFFECTS OF WATER LEVEL VARIATIONS ON THE STABILITY OF ROCK ARMOURED SLOPES
}

\author{
Marcel R.A. van Gent ${ }^{1}$, Suzanna A.A. Zwanenburg² and Jan Kramer ${ }^{3}$
}

\begin{abstract}
Physical model tests on the stability of rock armoured slopes have been performed to demonstrate the importance of water level variations during a storm, due to a tide or a storm surge. For the stability of rock armoured slopes also the importance of the sequence of storms at various water levels has been studied. The test results indicate that a smooth sinusoidal water level variation leads to an increase in damage compared to the same wave conditions at a constant water level. Furthermore, a stepwise approach of the sinusoidal water level elevation leads to other results than the approach with a continuous water level variation, whereas the continuous water level variation resembles the peak of a storm or the tidal water level variation better than a stepwise approach. If storms with different water levels attack the armour layer, the damage is generally smaller than if all storms attack the armour layer at the same water level. Furthermore, the results have been discussed based on earlier analyses where the statistics of rock armoured slopes have been addressed and the importance of the length effect has been illustrated using a method to apply results from physical model tests to real structures.
\end{abstract}

Keywords: rubble-mound breakwater; stability; rock slopes; tide; storm surge; storm peak; water level variations; armour layer; coastal structures; physical model tests; wave flume; statistics; length effect

\section{INTRODUCTION}

To evaluate the performance of coastal structures in terms of wave overtopping and the stability of the armour layer normally physical model tests are performed with a constant water level. However, in reality water levels vary during the peak of a storm due to the presence of storm surge and/or a tide. Coastal structures can also experience an accumulation of damage to the armour layer due to various storms, while each of the storms can occur at a different water level (see for instance Melby and Kobayashi, 1998, for armour layers and Van Gent et al, 2016, for effects of water level variations on material underneath the armour layer).

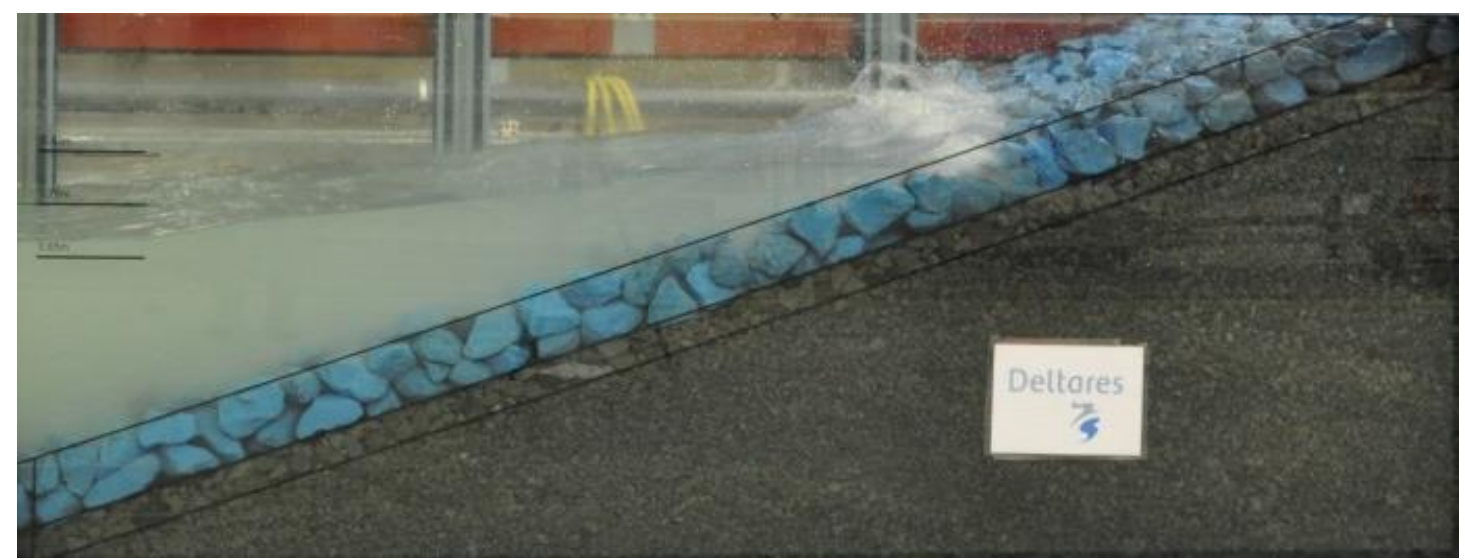

Figure 1. Picture of tested structure in wave flume.

In contrast to most physical model tests performed in the past, here tests have been performed with rock armoured slopes (Figure 1) with wave loading under various water levels, including tests with water levels that continuously vary during a single experiment, resembling a tide (Figure 3; lower right panel). To our knowledge such wave loading tests with continuous water level variations resembling a tide (with corresponding active wave absorption and second order wave generation) have not been performed before. The armour stability has been compared to results from tests with a sequence of conditions with constant still water levels (Figure 3; lower left panel) and increasing and decreasing water levels in steps, each with a constant still water level (Figure 3; upper panels). Also a reference

\footnotetext{
${ }^{1}$ Coastal Structures \& Waves, Deltares, Delft, The Netherlands, Marcel.vanGent@deltares.nl

${ }^{2}$ Coastal Structures \& Waves, Deltares, Delft, The Netherlands, Suzanna.Zwanenburg@deltares.nl

${ }^{3}$ Coastal Structures \& Waves, Deltares, Delft, The Netherlands, Jan.Kramer@deltares.nl
} 
case with a constant still water level has been tested. These tests have been performed with relatively deep water at the toe of the structure (no wave breaking on the foreshore). The test results on the stability of rock armoured slopes provide an indication of the importance of water level variations during a storm and the importance of the sequence of storms on the accumulative damage.

Besides water level variations due to a tide or storm surge, sea level rise can also cause that in a later stage of the lifetime structures can experience wave conditions at a higher water level than directly after construction. Such water level variations due to sea level rise are also important for the cumulative damage to the structure during its lifetime. In the presence of a shallow foreshore an increased water level not only affects the location of the maximum wave loading, also the loading itself increases for higher water levels. Therefore, Van Gent et al (2018) performed physical model tests with the same offshore wave conditions but, due to increasing water levels, an increased wave loading on the structure. This provided information on the importance of water levels for rock armoured slopes on the long-term.

The present paper focusses on water level variations due to a tide or storm surge, and a sequence of storms at various water levels.

\section{PHYSICAL MODEL TESTS}

The physical model tests have been performed in the Scheldt Flume of Deltares, Delft. This flume has a length of $110 \mathrm{~m}$ (of which $55 \mathrm{~m}$ has been used for the present tests), a width of $1 \mathrm{~m}$ and a height of $1.2 \mathrm{~m}$. The active reflection compensation system (ARC, see also Wenneker et al., 2010) is able to account for continuously changing water levels, resembling a tide. The new feature of the wave flume to control the water level variation in accordance with a prescribed water level signal has been implemented based upon $a$ ) taking the prescribed water level variation into account in the wave board steering process, $b$ ) controlling the pump system to pump water in and out of the flume, and $c$ ) real-time measuring the mean water levels to correct for potential difference between the actual and prescribed water levels by coupling the water level measurements to the pump system. Of course the measured water levels need to be processed in order to filter out the waves from the water level signals.

The tested structure (Figures 1 and 2) consists of an armour layer of rock $\left(D_{n 50, a}=63 \mathrm{~mm} ; d_{a}=\right.$ $\left.2 D_{n 50, a}=126 \mathrm{~mm} ; D_{n 85, a} / D_{n 15, a}=1.5\right)$ on top of an underlayer of rock $\left(D_{50, f}=0.029 \mathrm{~m} ; d_{f}=64 \mathrm{~mm}\right.$; $\left.D_{85, f} / D_{15, f}=2.5\right)$ and a core of rock $\left(D_{50, \mathrm{c}}=0.011 \mathrm{~m} ; D_{85, c} / D_{15, c}=2.7\right)$. The slope was 1:3. The crest level was at $1.2 \mathrm{~m}$ above the bottom of the flume. With the tested water levels between $h=0.65 \mathrm{~m}$ and $h=0.85 \mathrm{~m}$ this means that the structures was basically non-overtopped. No wave breaking occurred on the horizontal foreshore.

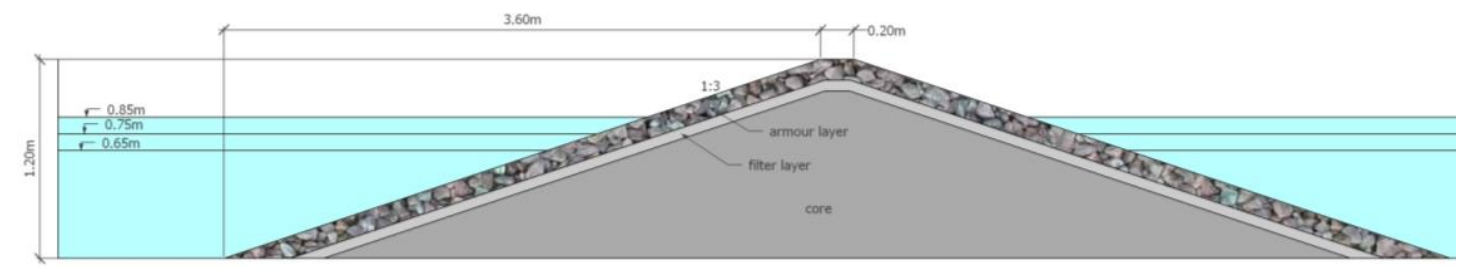

Figure 2. Tested structure in the wave flume.

The structure was tested with two incident wave conditions, one with a wave steepness of $s_{o p}$ $=0.016\left(H_{s}=0.212 \mathrm{~m}\right.$ and $\left.T_{p}=2.93 \mathrm{~s} ; s_{o p}=2 \pi H_{m o} /\left(g T_{p}^{2}\right)\right)$ and one with $s_{o p}=0.039\left(H_{s}=0.260 \mathrm{~m}\right.$ and $T_{p}$ $=2.06 \mathrm{~s}$ ). A JONSWAP spectrum was used. The incident waves were measured in front of the toe of the structure.

The damage to the armour layer was measured using a mechanical profiler. Nine individual profiles were measured over the flume width of $1 \mathrm{~m}$; the distance between the individual profiles was $0.1 \mathrm{~m}$. The profiles of the armour layer were measured at the beginning and end of each test condition. The damage values were obtained from the total area of erosion $\left(A_{e}\right)$, being the difference between the averaged initial and averaged end profiles. The eroded area $\left(A_{e}\right)$ was made non-dimensional with the stone diameter squared: $S=A_{e} / D_{n 50}^{2}$.

Five series of tests were performed, each with two wave conditions; one with a low wave steepness and one with a high wave steepness. Each wave condition was tested with a total duration of 3000 waves per series of tests. Series A are the reference tests with a constant still-water level of $h=0.75 \mathrm{~m}$ (3000 waves). In Series B the water level was increased in 3 steps: 1000 waves at a water level of 
$h=0.65 \mathrm{~m}, 1000$ waves at a water level of $h=0.75 \mathrm{~m}$, and 1000 waves at a water level of $h=0.85 \mathrm{~m}$. In Series $C$ the water level was decreased in 3 steps: 1000 waves at a water level of $h=0.85 \mathrm{~m}, 1000$ waves at a water level of $h=0.75 \mathrm{~m}$, and 1000 waves at a water level of $h=0.65 \mathrm{~m}$. Series D resembles a peak of a storm or a stepwise tidal variation: 500 waves at a water level of $h=0.65 \mathrm{~m}, 500$ waves at a water level of $h=0.75 \mathrm{~m}, 1000$ waves at a water level of $h=0.85 \mathrm{~m}, 500$ waves at a water level of $h=0.75 \mathrm{~m}$, and 500 waves at a water level of $h=0.65 \mathrm{~m}$. Series E resembles a peak of a storm or a smooth sinusoidal tidal variation that consists of 3000 waves. Figure 3 shows the water level variations in Series B to E. After each test series the damage was measured and repaired to proceed with the next test series.
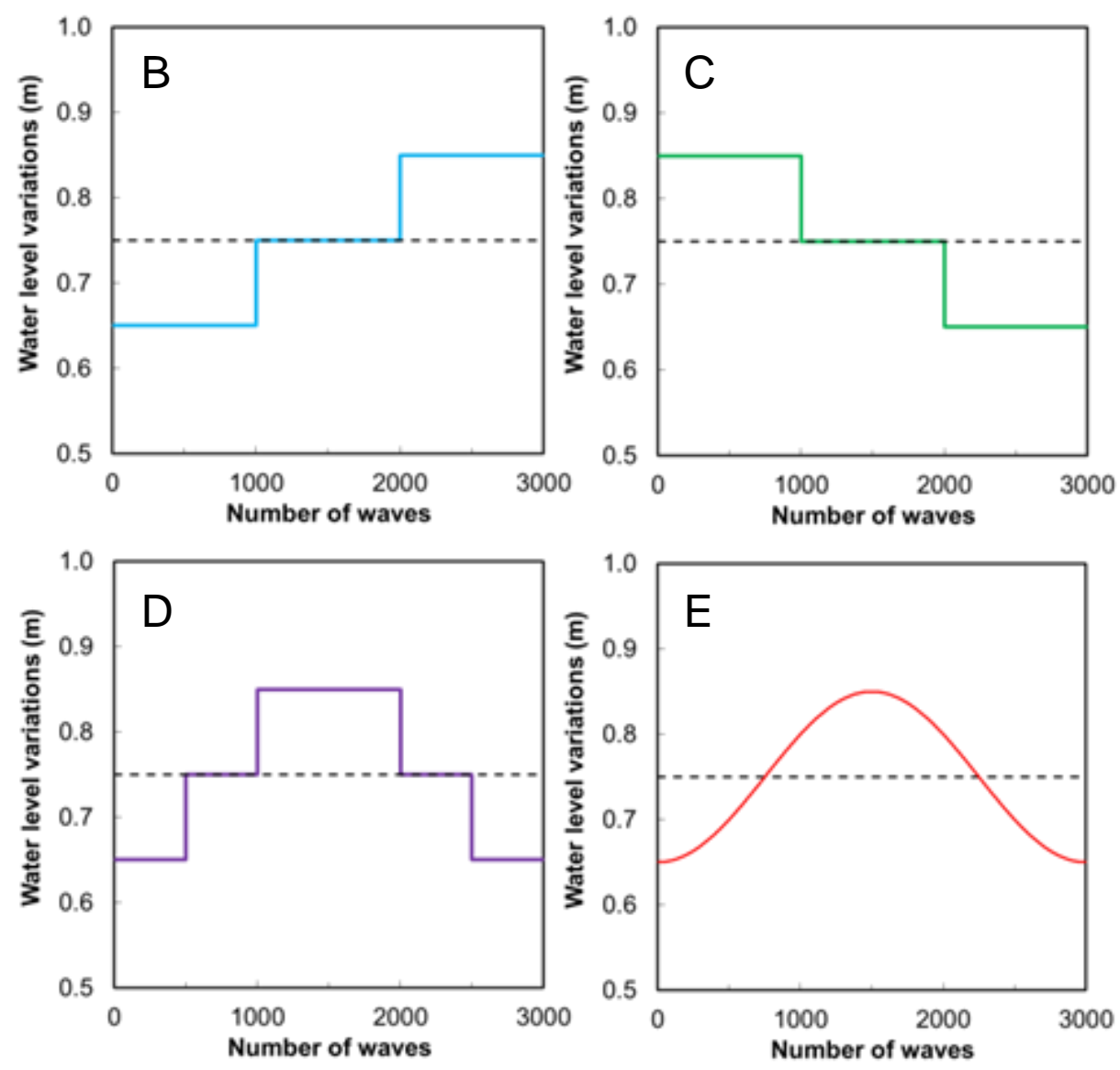

Figure 3. Scenarios of tested water level variations.

\section{TEST RESULTS}

In Table 1 the measured damage levels are listed for the low wave steepness conditions and for the high wave steepness conditions. The differences between the measured damage levels compared to the reference tests with a constant water level are listed as well (last two columns in Table 1).

\begin{tabular}{|c|l|c|c|c|c|c|}
\hline \multicolumn{2}{|c|}{ Table 1 Measured damage } & \multicolumn{2}{c|}{ Damage } & \multicolumn{2}{c|}{ Differences } \\
\cline { 3 - 7 } & \multicolumn{2}{|c|}{} & $s_{o p}=0.016$ & $s_{o p}=0.039$ & $s_{o p}=0.016$ & $s_{o p}=0.039$ \\
\hline \multirow{2}{*}{ Series } & Name & $h(m)$ & $S$ & $S$ & $\%$ w.r.t. & $\%$ \%. W.r.t. \\
& & 0.75 & 3.7 & 4.3 & - & - \\
\hline A & Constant water level & $0.65-0.75-0.85$ & 2.8 & 3.9 & $-24 \%$ & $-9 \%$ \\
B & Increasing water level & $0.85-0.75-0.65$ & 2.2 & 3.7 & $-40 \%$ & $-14 \%$ \\
C & Decreasing water level & $0.65-0.75-0.85-0.75-0.65$ & 3.1 & 5.3 & $-16 \%$ & $+23 \%$ \\
D & Stepwise tide & $0.65-0.85-0.65$ & 4.3 & 4.9 & $+16 \%$ & $+14 \%$ \\
E & Sinusoidal tide & & & & &
\end{tabular}


The test results show the following:

- The feature of the wave flume to generate a specified sinusoidal water level variation during a test performs properly; the water level variation follows the specified signal and the measured wave conditions correspond to the prescribed wave conditions (i.e. the desired and actual water level variation as shown in Figure 3, lower right panel, are close to equal).

- Series B with stepwise increased water levels shows less damage than the same wave conditions at a constant water level (References test: Series A): A reduction of $24 \%$ for the low wave steepness and a reduction of $9 \%$ for the high wave steepness.

- Series $\mathrm{C}$ with stepwise decreased water levels shows less damage than the same wave conditions at a constant water level (References test: Series A): A reduction of $40 \%$ for the low wave steepness and a reduction of $14 \%$ for the high wave steepness. The damage values are somewhat lower (and the reduction is somewhat larger) than for the stepwise increased water levels (Series B).

- Series D with a stepwise peak of a storm or a stepwise tidal variation does not show a consistent increase or decrease compared to the same wave conditions at a constant water level (References test: Series A): A reduction of $16 \%$ for the low wave steepness and an increase of $23 \%$ for the high wave steepness.

- Series E with a smooth sinusoidal water level variation shows an increase in damage compared to the same wave conditions at a constant water level (References test: Series A): An increase of $16 \%$ for the low wave steepness and an increase of $14 \%$ for the high wave steepness.

- The sinusoidal water level variation (Series E) resembles the peak of a storm or the tidal water level variation better than a stepwise approach (Series D). The stepwise approach leads to other results than the approach with a continuous water level variation (see results of Series D and E in Table 1).

- Series B and Series C indicate that if storms with different water levels attack the armour layer, the damage is smaller than if all storms attack the armour layer at the same water level.

- The differences between damage for conditions with sinusoidal water level variations (Series E) and a constant water level (Series A) seem to be in the order of magnitude of $15 \%$. This magnitude, and the fact that the damage is larger for the sinusoidal water level variation, indicates that water level variations during a storm cannot be neglected and need to be accounted for.

\section{DISCUSSION OF TEST RESULTS}

\section{Results in relation to standard deviations}

In Van Gent et al (2018) a statistical analysis was performed for the stability of rock slopes. In those tests 54 stones over the width of the test section were used while in the present tests the number of stones in the width of the flume was $1000 \mathrm{~mm} / 63 \mathrm{~mm}=16$, which is significantly less than the number of stones in those tests on which the standard deviations were based. In Van Gent et al (2018) the standard deviation was estimated by using $\sigma=0.3 S^{0.2}$ (based on a width of the test section of 54 stones). The standard deviation of the test results is likely to be larger in the present tests than for tests with a larger number of stones over the width of the flume. For 16 stones within the width of the flume, the results presented in Van Gent et al (2018, Figure 8a, blue line) indicate that the standard deviation is $\sigma=1.3$ for an $S$ value of about $S=4$ (while if a width of 54 stones would have been used, the standard deviation would be estimated at 0.4 using the proposed expression $\sigma=0.3 S^{0.2}$ ). The observed differences between Series A and Series E are less than one standard deviation of $\sigma=1.3$. Most mutual differences between test results of various test series are within 1 standard deviation. Although the differences seem to be rather systematic, the number of tests (or number of stones within the width of the flume) is not sufficient to draw final conclusions on the magnitude of the importance of smooth sinusoidal water level variations, or the magnitude of the importance of the sequence of various storms. Nevertheless, it can be stated that the present tests provide a clear indication that the sequence of storms is important and that a smooth water level variation in reality should not be modelled by a stepwise water level variation to model a tide or the peak of storm. However, on the magnitude of the importance no firm conclusions can be drawn.

\section{Length effect}

In Van Gent et al (2018) the importance of the length effect of structures is addressed. To illustrate the importance of the length effect, the present tests are supposed to be a representation of a real structure with a length of $1000 \mathrm{~m}$, while the model tests have a scale of $1: 25$. Using the estimate of a 
standard deviation of $\sigma=1.3$ for the present tests, the probability that the maximum allowable damage of $S=6$ is exceeded in any position over the width of the flume is $\mathrm{P}(S>6)=0.04$ in the case of Series A with a wave steepness of $s_{p}=0.016$ (using Eq. 1 from Van Gent et al, 2018), while the probability that $S=6$ is exceeded in any position over the width of the real structure is $\mathrm{P}(S>6)=0.79$ (using Eq.2 from Van Gent et al, 2018). For Series E, the corresponding values are $\mathrm{P}(S>6)=0.10$ within the flume and $\mathrm{P}(S>6)=0.98$ for the structure in reality. This illustrates that if the tidal variation is included (Series A compared to Series E) the probability that the maximum allowable damage would be exceeded in any position within the flume increases from $4 \%$ to $10 \%$ while the probability that the maximum allowable damage would be exceeded in reality increases from $79 \%$ to $98 \%$. Although the probability of $4 \%$ that the maximum damage would be exceeded (for a structure in the flume without tidal variation) could be considered as acceptable, a probability of $98 \%$ that the maximum allowable damage would be exceeded (for a structure in reality with tidal variation) clearly cannot be acceptable. This illustrates that ignoring both the influence of water level variations and also the length effect (which is the current standard practice), can lead to estimates of the probability of exceeding acceptable damage levels that are much too low.

\section{CONCLUSIONS}

To analyse effects of water level variations, an existing wave flume has been equipped with an additional feature, namely continuous water level variations during a test, resembling a tide or storm surge during a storm.

The performed tests show the importance of water level variations on the response of rock armoured slopes. This is important within a single storm (tide) and for a series of storms with different water levels, including the sequence of storms.

- A smooth sinusoidal water level variation (i.e. during the peak of the storm or resembling a tide) shows an increase in damage compared to the same wave conditions at a constant water level.

- A stepwise approach of the sinusoidal water level elevation leads to other results than the approach with a continuous water level variation, whereas the continuous water level variation resembles the peak of a storm or the tidal water level variation better than a stepwise approach.

- If storms with different water levels attack the armour layer, the damage is generally smaller than if all storms attack the armour layer at the same water level.

- To draw firm conclusions on the magnitude of the influence of tidal water level variations more test series are needed. In the present tests the differences between damage for conditions with sinusoidal water level variations and with a constant water level were in the order of magnitude of $15 \%$.

Since in 2D physical model tests structures are generally less wide than the real (prototype) structures that they resemble, the difference between the scaled width of the structure in the model and the width of the structure in reality needs to be taken into account. Expressions to take this length effect into account by Van Gent et al (2018) have been applied to illustrate the importance of the length effect.

\section{ACKNOWLEDGEMENTS}

We would like to thank Ing. Martijn Smeulers (Deltares) for his valuable activities to add the new wave flume feature of continuous varying water levels during a test.

\section{REFERENCES}

Melby, J.A. and N. Kobayashi. 1998. Progression and variability of damage on rubble mound breakwaters, J. of Waterway, Port, Coastal and Ocean Engrg 124(6), 286-294.

Van Gent, M.R.A., G. Wolters and I.M. van der Werf. 2016. Rock slopes with open filters under wave loading: Effects of storm duration and water level variations; Proc. ICCE 2016, Antalya, Turkey.

Van Gent, M.R.A., E. de Almeida and B. Hofland. 2018. Statistical analysis of the stability of rock armoured slopes, Proc. Coastlab 2018, Santander.

Wenneker, I., J. Meesters, R. Hoffmann, D. Francissen. 2010. Active wave absorption system ARCH, Proc. Coastlab 2010, Barcelona. 